\title{
Glycogen in Human Peripheral Blood Leukocytes
}

\section{THE MACROMOLECULAR STATE OF LEUKOCYTE GLYCOGEN}

\author{
Robert B. SCOTt and W. J. S. STILL with the technical assistance of \\ LAVERNE W. COOPER \\ From the Departments of Medicine and Pathology, Medical College of Virginia, \\ Richmond, Virginia
}

A в S T R A C т Glycogen of normal human blood leukocytes was studied in cell suspensions containing chiefly neutrophiles.

In electron micrographs of neutrophiles stained with lead the glycogen particles appear to be relatively uniform with a diameter of $20 \mathrm{~m} \mu$. At high magnification the $20 \mathrm{~m} \mu$ particle appears to be composed of at least eight subunits.

Leukocyte glycogen released by lysis or homogenization sediments as a single peak of high molecular weight material. The great majority of the cell glycogen can be accounted for in the large molecular weight material. The large molecular weight material is degraded to small fragments by $\alpha$-amylase and partially degraded by $\beta$-amylase. Purification of cell glycogen by alkali extraction and ethanol precipitation produces a relatively uniform particle smaller than the original native macromolecule.

Native glycogen was prepared in pure form by a sucrose density gradient technique and its purity demonstrated by its susceptibility to purified $\alpha$ amylase and by analytical ultracentrifugation.

\section{INTRODUCTION}

Peripheral blood leukocytes contain consideralle amounts of glycogen $(1,2)$, and since they are

Part of this work appeared in abstract form in J. Clin. Invest. 1967. 46: 1116.

Address requests for reprint to Dr. Robert B. Scott, Department of Medicine, Medical College of Virginia, Richmond, Va. 23219.

Recio'ed for publication 29 . Lugust 1967 and in reised form 9 Octoher 1967. readily accessible, provide a convenient system in which glycogen metabolism can be studied. In a preceding paper (3) studies involving suspensions of leukocytes (chiefly neutrophiles), were reported and some aspects of glycogen synthesis, degradation, and turnover were described.

In the present paper these studies were extended to demonstrate the particulate or macromolecular state of leukocyte glycogen. These stuclies show that glycogen exists in leukocytes as a group of molecules of similar size and that synthesis and degradation involve adding and subtracting glucose resiclues uniformly from all molecules rather than synthesizing entirely new molecules or breaking down single molecules. Electron microscopic eviclence of a subunit structure of the predominant glycogen particle is also presented.

\section{METHODS}

Prcparation of leukocyte suspensions. Leukocyte suspensions containing an average of $83 \%$ granulocytes were prepared from normal adult donors by combined dextran sedmentation and differential centrifugation as previously described (3). Hypotonic lysis of contaminating erythrocytes was usually omitted. If erythrocytes contain glycogen, the quantity is quite small (4) compared to granulocytes and its contribution was neglected. Cells were suspended in glucose-free Hanks' (GFH) solution containing penicillin and streptomycin for incubation.

Incorporation of glucose $-{ }^{14} \mathrm{C}$ into glycogen. In order to insure adequate incorporation of label during glycogen synthesis, we preincubated the cells first in GFH solution for $2 \mathrm{hr}$ which resulted in a loss of about one-third of the glycogen stores (3). Uniformly labeled glucose $-{ }^{14} \mathrm{C}$ (specific activity $172 \mathrm{mc} / \mathrm{mm}$ (le) 1 was diluted in sterile

${ }^{1}$ New England Nuclear Corp., Boston, Mass. 


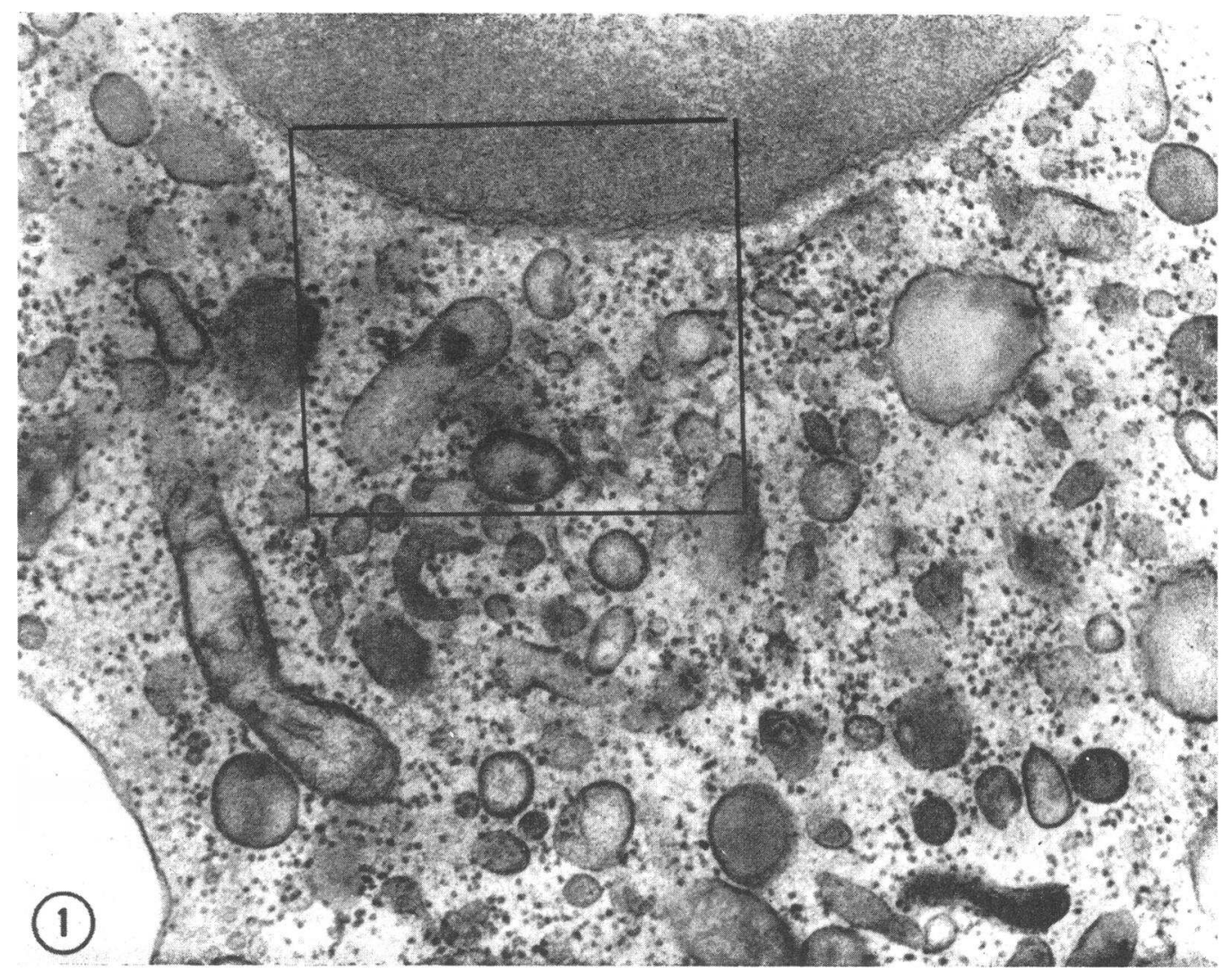

FIgURE 1 Electron micrograph of a portion of a neutrophile granulocyte. Osmium-fixed preparation showing a portion of the nucleus and numerous specific granules in the cytoplasm. Glycogen is seen as small, dense, uniform particles scattered throughout. $\times 40,000$.

$10 \%$ glucose. For long label $(2-4 \mathrm{hr})$ the label was diluted to $0.172 \mathrm{mc} / \mathrm{mmole}$ and for shorter labels the dilution was 1.72 or $0.86 \mathrm{mc} / \mathrm{mmole}$. Radioactive glucose was added to the suspensions in GFH in concentrations of $50-100 \mathrm{mg} / 10^{\circ}$ neutrophiles. Incubations were performed in air at $37^{\circ} \mathrm{C}$ without agitation.

Preparation of cell lysates and homogenates. After incubation in glucose $-{ }^{14} \mathrm{C}$, the cells were iced, washed three times with cold isotonic saline, and lysed in $0.34 \mathrm{M}$ sucrose by a procedure similar to that described by Cohn and Hirsch for rabbit leukocytes (5). The leukocyte pellet was resuspended in $0.5 \mathrm{ml}$ of $0.34 \mathrm{M}$ sucrose, $0.01 \mathrm{M}$ Tris, $\mathrm{pH} 8$ and vigorously agitated by aspirating and expelling the cells through a 20 gauge needle on a $1 \mathrm{ml}$ syringe. It was necessary to repeat the procedure with three additional $0.5 \mathrm{ml}$ volumes of sucrose in order to lyse most of the cells in the pellet as determined by phase microscopy. The mixture was then spun at $1000 \mathrm{~g}$ for 5 $\min$ and the supernate separated. The supernates were pooled and then diluted with $0.75-1.0$ volumes of $0.01 \mathrm{M}$ Tris $\mathrm{pH} 8$ in order to be layered on top of sucrose density gradients. In some later experiments the cells were homogenized rather than lysed. For homogenization, the washed cells were suspended in 1 or $2 \mathrm{ml}$ of $0.01 \mathrm{M}$ Tris
pH 8 and broken with 15 strokes of a "no-clearance" homogenizer. ${ }^{2}$ This was sufficient to release $80-90 \%$ of the cell glycogen; the remaining glycogen was apparently firmly bound to cell structures. Homogenates were centrifuged at $1000 \mathrm{~g}$ for $10 \mathrm{~min}$ and the supernate layered on sucrose density gradients. Identical results were obtained with both homogenization and osmotic lysis.

Radioactive glycogen was also purified from whole cells as previously described (3).

Ultracentrifugation procedures. Linear sucrose density gradients were prepared with $10-25 \%$ sucrose $(\mathrm{w} / \mathrm{w})$ in $0.01 \mathrm{M}$ Tris $\mathrm{pH} 8$ with total volume $28 \mathrm{ml}$. $1-1.5 \mathrm{ml}$ of cell lysate or homogenate was layered on each gradient and spun at $24,000 \mathrm{rpm}$ in an SW 25.1 rotor in a model L-2 ultracentrifuge 3 at $5^{\circ} \mathrm{C}$. After centrifugation the bottom of the tube was punctured with an 18 gauge needle and $0.8 \mathrm{ml}$ fractions collected. One drop of each fraction was removed and counted at infinite thinness in a low background gas-flow counter.*

Electron microscopy. Pellets of white cells were fixed in $1 \%$ buffered osmium tetroxide (6) for $1 \mathrm{hr}$ at $4^{\circ} \mathrm{C}$.

2 Kontes Glass Co., Vineland, N. J.

3 Beckman Instruments, Palo Alto, Calif.

4 Nuclear-Chicago Corp., DesPlaines, IIl. 


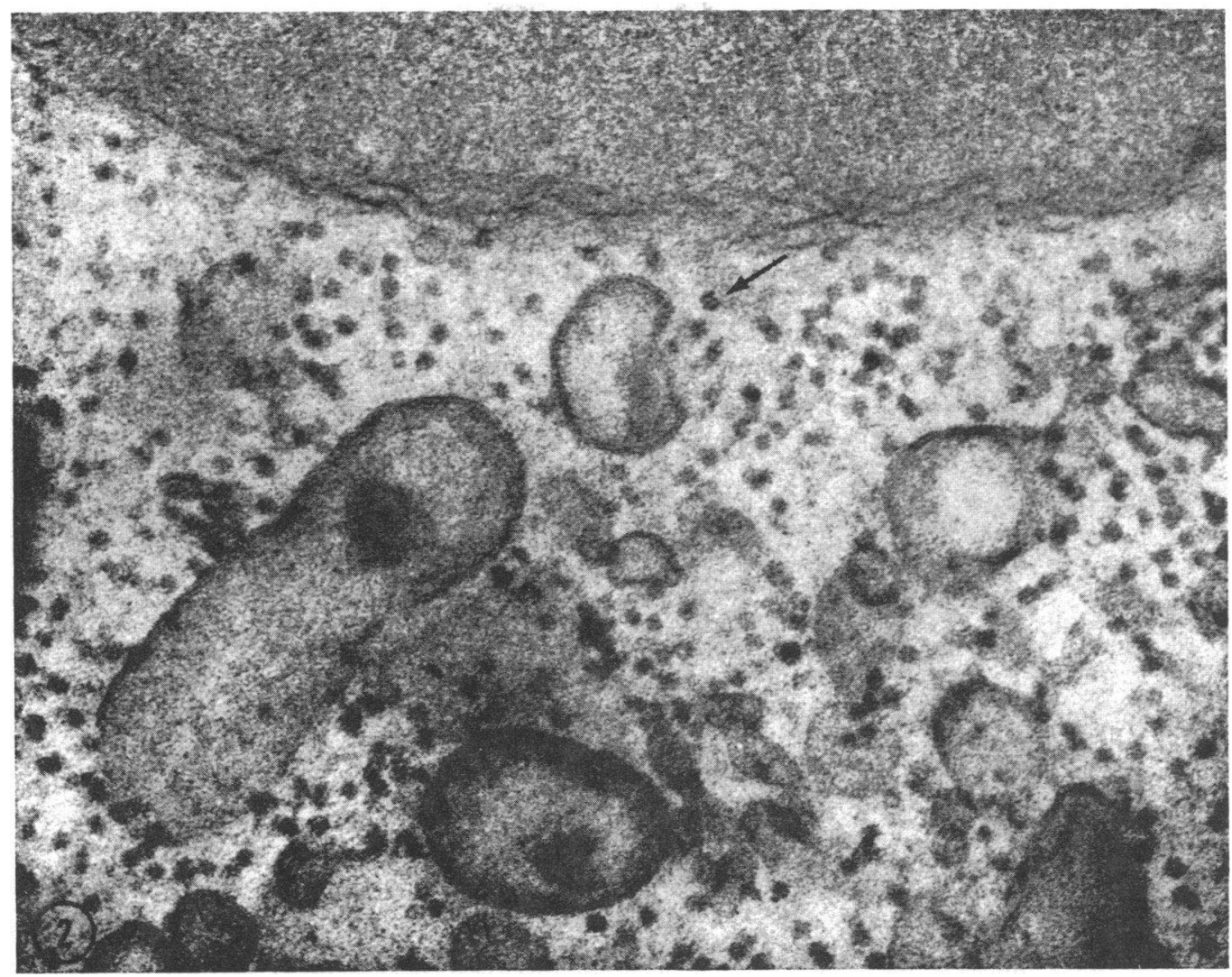

FIGURE 2 Higher magnification of the area outlined in Fig. 1. Some of the particles appear to have a substructure composed of rounded units. The arrow points to one showing at least eight subunits. $\times 100,000$.

After dehydration in graded ethanols the pellets were embedded in Maraglas D.E.R. (7). Thin sections were prepared, stained with lead acetate, and viewed in a Siemens Elmiskop $I^{5}$ at $80 \mathrm{kv}$. Purified $\alpha$-amylase ${ }^{B}$ and $\beta$-amylase ${ }^{7}$ were obtained commercially.

\section{RESULTS}

The size and substructure of leukocyte glycogen particles. A suspension of leukocytes from a normal donor was prepared in which the glycogen content was found to be $7.1 \mathrm{mg}$ glycogen $/ 10^{\circ}$ neutrophiles. The cells were fixed as described in Methods and visualized in the electron microscope. A portion of a granulocyte is reproduced in Fig. 1 at a magnification of 40,000 showing the glycogen particles scattered randomly throughout the cytoplasm. The particles were discrete except in rare instances some aggregation was seen. A portion

5 Siemens America, Inc., N. Y.

6 Mann Research Laboratories, Inc., N. Y.

7 Sigma Chemical Co., St. Louis, Mo. of the same cell sample was incubated in glucosefree medium to deplete glycogen, and the cells were unchanged except that these particles had become too small to be readily resolved in the electron microscope. Measurements of particle size were made at higher magnification (Fig. 2). The results of 528 individual measurements, which illustrate that the majority of the particles were 20 $\mathrm{m} \mu$ in diameter, are shown in Fig. 3. At high magnification there appears to be a regular substructure to the particles composed of smaller subunits. The particle near the arrow in Fig. 2 shows at least eight subunits.

The sedimentation of particulate glycogen in sucrose density gradients. Leukocyte suspensions were incubated in glucose $-{ }^{14} \mathrm{C}$ and lysates or homogenates prepared as described under Methods. Fig. 4 illustrates one such experiment in which leukocytes were labeled with glucose- ${ }^{14} \mathrm{C}$ for $1 \mathrm{hr}$. The homogenate was spun through linear $10-25 \%$ 


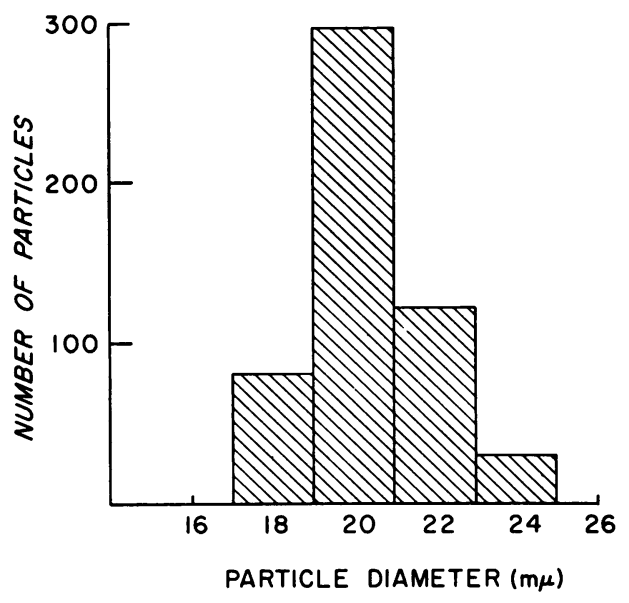

FIGURE 3 Size distribution of leukocyte glycogen particles. Measurements were made of 528 glycogen particles on the plate shown in Fig. 1. The greatest number of particles were $20 \mathrm{~m} \mu$ in diameter.

sucrose density gradients for $210 \mathrm{~min}$ at 24,000 rpm. One-half of the sample was treated with crystallized pancreatic $\alpha$-amylase $(50 \mu \mathrm{l} / \mathrm{ml}$ for $20 \mathrm{~min}$ at $4^{\circ} \mathrm{C}$ ) before layering on a gradient.

The untreated sample shows a relatively homogeneous group of large radioactive particles and additional radioactivity in smaller material at the top of the gradient. The total number of counts recovered under the large peak (samples 1-28) account for $78.5 \%$ of the total radioactivity in the gradient. Since under the conditions of labeling approximately $80 \%$ of the ultracellular radioactivity should be found in glycogen (3), the great majority of the cell glycogen is accounted for by the material under the heavy peak. The particles are probably not completely uniform in size as evidenced by the spreading of the base of the large peak. The curve designated " $\alpha$-amylase" shows that the material under the large peak was broken to smaller fragments by $\alpha$-amylase treatment.

What proportion, if any, of the radioactive small molecular weight material in the untreated sample is glycogen cannot be determined. However, similar preparations were centrifuged for $13,20,60$, and $80 \mathrm{hr}$ at $24,000 \mathrm{rpm}$ and failed to show any other peaks of lighter particulate material.

Effect of $\beta$-amylase or alkali extraction on sedimentation of glycogen. Alpha amylase will degrade glycogen almost entirely while $\beta$-amylase will remove glucose units down to a branch point of the chain but no farther. Fig. 5 illustrates the change in sedimentation after $\beta$-amylase treatment. Leukocytes were incubated in glucose- ${ }^{14} \mathrm{C}$ for $3 \mathrm{hr}$. One-half of the lysate was treated with sweet potato $\beta$-amylase $\left(50 \mu \mathrm{l} / 2 \mathrm{ml}\right.$ for $20 \mathrm{~min}$ at $4^{\circ} \mathrm{C}$ ) after which the samples were layered on sucrose density gradients. A sample of ${ }^{14} \mathrm{C}$-labeled glucose. alkali-extracted glycogen was run simultaneously to show the characteristic change in particle size induced by alkali. Centrifugation time was 210 min. The treated sample sedimented more slowly than the "native" glycogen but ahead of the peak of alkali-purified glycogen. The majority (65\%)

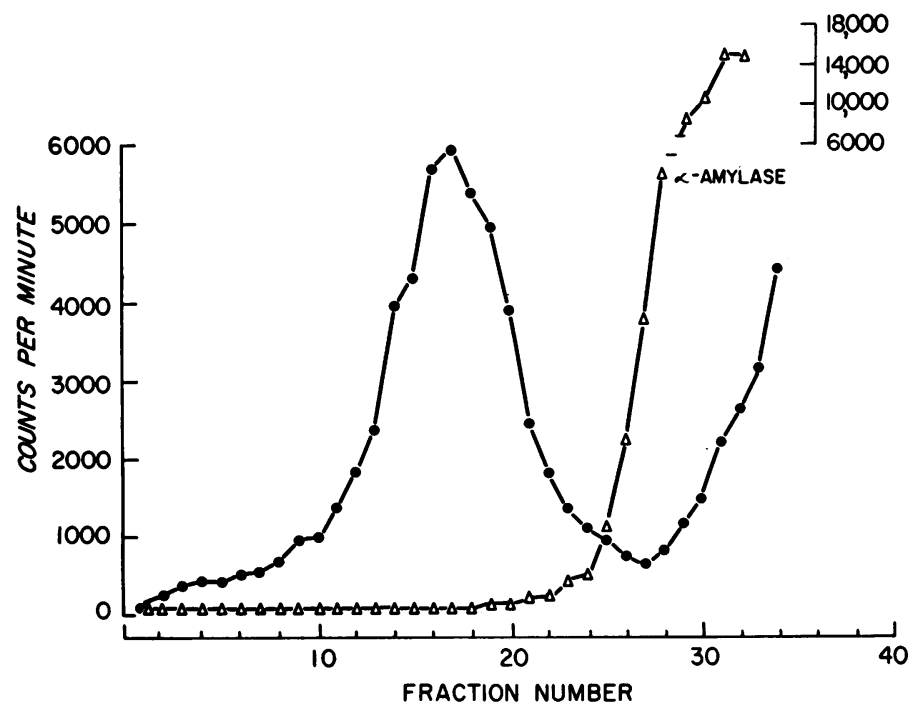

FIgURE 4 Sedimentation of native lcukocyte glycogen in sucrose density gradient. Leukocyte glycogen was made radioactive by incubation in glucose $-{ }^{14} \mathrm{C}$. The homogenate was centrifuged through a 10 $25 \%$ sucrose density gradient and sequential fractions collected as described in Methods. Direction of sedimentation to the left. Control preparation (๑), and a simultaneously run sample treated before centrifugation with $\alpha$-amylase $(\triangle)$. 


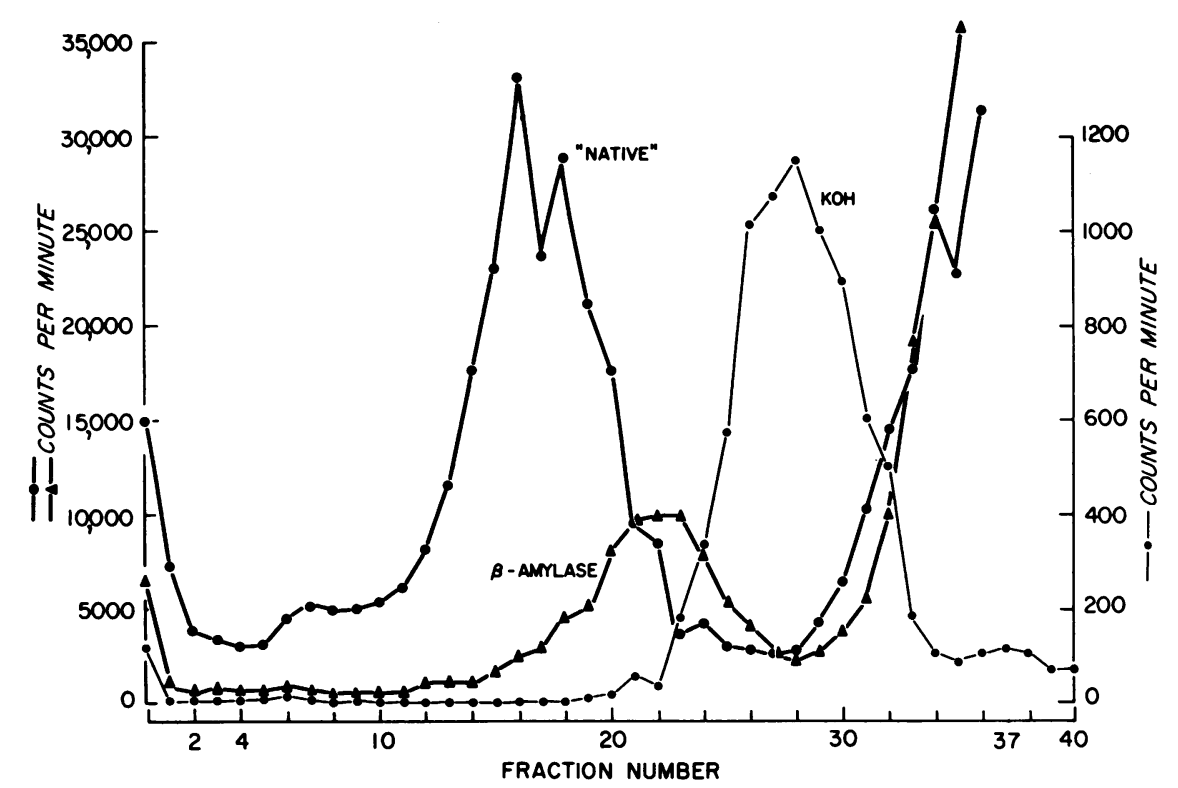

Figuke 5 Effect of beta amylase or alkali extraction on the sedimentation of leukocyte glycogen. One-half of a ${ }^{14} \mathrm{C}$-labeled homogenate was treated with $\beta$-amylase and run simultaneously with the control homogenate and a sample of alkali-purified leukocyte glycogen. Beta amylase acts to remove glucose units down to a branching point on the chain, thus removing the outer shell of the molecule.

of the counts in the "native" glycogen peak were solubilized by $\beta$-amylase treatment.

Scdimentation coefficient of "native" glycogen. $400 \mathrm{ml}$ of blood was collected from a normal donor and leukocyte suspensions prepared and counted. Small aliquots were removed for glycogen estimation. The remaining cells were homogenized and the homogenate divicled between three sucrose

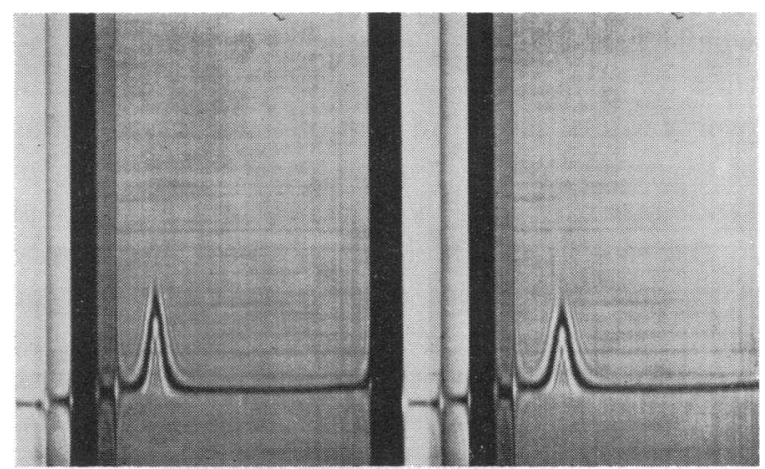

Figure 6 Schlieren patterns of leukocyte glycogen purified in sucrose density gradients. Frame on the left was taken $8.5 \mathrm{~min}$ after reaching speed of $15,220 \mathrm{rpm}$ and, on the right, after $12.0 \mathrm{~min}$. Glycogen was suspended in $0.01 \mathrm{~m}$ Tris $\mathrm{pH} 8$, concentration $2.2 \mathrm{mg} / \mathrm{ml}$. The single peak seen was completely degraded by $\alpha$-amylase treatment. gradients. The gradients were centrifuged as in Fig. 4. After collection of fractions, fractions corresponding to the large peak including its broad base (fractions 8-24) were pooled. The pooled fractions from the three gradients were then centrifuged at $28,000 \mathrm{rpm}$ in a No. 30 rotor for $6 \mathrm{hr}$. The glycogen pellet was resuspended in $0.6 \mathrm{ml}$ of warm $0.01 \mathrm{~m}$ Tris $\mathrm{pH} 8$. The slightly cloudy solution was then centrifuged in the model $\mathrm{E}$ analytical ultracentrifuge ${ }^{8}$ at $15,220 \mathrm{rpm}$ at $25^{\circ} \mathrm{C}$. The results are pictured in Fig. 6 . The original leukocytes contained $6.2 \mathrm{mg}$ glycogen $/ 10^{\circ}$ neutrophiles. The solution of "native" glycogen contained $2.2 \mathrm{mg} / \mathrm{ml}$. The single peak seen in Fig. 6 had a sedimentation coefficient of $125 \mathrm{~S}$ and was completely broken down by $\alpha$-amylase treatment.

\section{DISCUSSION}

The glycogen macromolecule, being in a state of constant turnover, varies in size depending on the relative rates of synthesis and degradation. Characterization of the molecule, as presented here, shows an order of magnitude for the dimensions and sedimentation coefficient of the molecule in

\footnotetext{
8 Beckman Instruments, Palo Alto, Calif.
}

Macromolecular Leukocyte Glycogen 
leukocytes and correlates these with the glycogen content of the cells from which it was extracted.

Glycogen structure in liver differs from that in leukocytes in that glycogen molecules in liver appear as a spectrum of sizes rather than a relatively uniform particle size as in leukocyte glycogen. Drochmans (8) studied rat liver glycogen by electron microscopy and was able to disaggregate the large (40-200 $\mathrm{m} \mu$ ) molecules into smaller units of uniform size by lowering the $\mathrm{pH}$ below 5.0. The uniform particles produced were spheres of $30 \mathrm{~m} \mu$ diameter. These particles appeared to have subunits which he described as being filaments $3 \mathrm{~m} \mu$ in diameter and $20 \mathrm{~m} \mu$ long. The largest particles were called $\alpha$-, the $30 \mathrm{~m} \mu$ particles designated $\beta$-, and the smallest subunits $\gamma$-particles. Barber, Harris, and Anderson (9) studied rat liver glycogen by electron microscopy and centrifugation in density gradients and described a spectrum of particle sizes up to $200 \mathrm{~m} \mu$ with sedimentation coefficients up to 10,000 . They observed, like Drochmans, that the $\alpha$-particles were aggregates of varying numbers of uniform $\beta$-particles of 20-25 $\mathrm{m} \mu$ diameter. They believed, however, that the $\gamma$-particle was a sphere $2.5-3.5 \mathrm{~m} \mu$ in diameter rather than a filament as Drochmans described. Leukocyte glycogen appears as uniform size particles $20 \mathrm{~m} \mu$ in diameter and probably corresponds to the $\beta$-particles described in rat liver. The leukocyte particles likewise contain subunits, at least eight in some particles. Why liver $\beta$-particles aggregate is unknown. The nature of the binding of $\gamma$-particles into a $\beta$-particle is likewise unclear.

Labeling of glycogen with glucose $-{ }^{14} \mathrm{C}$ during a period of active glycogen synthesis, as in the sucrose gradient experiments, permits some conclusions as to the assembly of the macromolecule. If the predominant particle ( $\beta$-particle) is produced by a stepwise addition of subunits ( $\gamma$-particles) then a spectrum of particle sizes in the density gradient would appear. This is not the case, which indicates that existing $\beta$-particles are enlarged uniformly during glycogen synthesis. New glucose units are probably added individually although some small subparticle could conceivably add to the $\beta$-particles. Extended centrifugation (up to $80 \mathrm{hr}$ at $24,000 \mathrm{rpm}$ ) revealed no lighter peaks, so if smaller subunits exist they must exist very transiently. If smaller particles exist free in the leukocyte homogenates, they are not likely to exist in large amount since, as illustrated in Fig. 4, the large glycogen peak accounts for nearly all of the ${ }^{14} \mathrm{C}$ counts to be expected from labeling under the conditions of the experiment.

It is of interest that extraction of glycogen by alkali produces a discrete particle, smaller than the original $\beta$-particles (Fig. 5). The exact nature of the change in the molecule which makes it smaller than a $\beta$-particle but still larger than the presumed $\gamma$-particle size is not known.

The experiment (Fig. 5) illustrating the action of $\beta$-amylase on glycogen shows an incomplete degradation of the molecule. Beta amylase action stops at a branch point in the glycogen chain and the action of the "debrancher" enzyme, dextrin-1, glucosidase, is required before further $\beta$-amylase activity is possible. Although the molecules appear to be only slightly smaller, judging from their sedimentation, the radioactivity associated with the peak is only about one-third as great as the control. This rough comparison suggests, as is known to be the case with liver glycogen (10), that the outer chains of the molecule are the most metabolically active.

From these studies of the macromolecular form of leukocyte glycogen, and from the studies of the dynamic state of the molecule in the preceding paper (3), one can begin to understand the functional or "native" state of the molecule in the cell. Glycogen synthesis and degradation proceed rapidly even when the total amount of glycogen in the cell is constant. When endogenous glucose is needed, the glycogen level falls rapidly and when glucose is replaced, the glycogen stores return to normal. Despite the constant rapid turnover and fluctuation in size of the glucose chains of glycogen, the enzymatic machinery (glycogen synthetase and phosphorylase) which is attached to the molecule $(11,12)$ is turned over slowly if at all. The number of glycogen molecules (or $\beta$-particles) in the cell probably is fixed since degradation and resynthesis involve all molecules equally, and during resynthesis, no sequential assembly of new molecules was detected. It is, of course, possible that $\beta$-particles might be completely assembled so rapidly that intermediate size particles are undetectable, but this would require a sizable pool of subunits ( $\gamma$-particles) which were not detected.

What fixes the number of glycogen molecules 
in the cell? How are the molecules first assembled during the differentiation of the leukocyte? Are the enzymes of glycogen synthesis and degradation fixed to some structural component of the glycogen $\beta$-particle, or do they attach and reattach as needed? These are some of the important questions posed by the present knowledge of glycogen in leukocytes and other tissues.

Particulate or "native" glycogen as visualized in the cell is not a molecule in the ordinary static sense, but a dynamic "organelle" whose product is fuel in the form of glucose. These organelles, for which we have applied the term "glycosomes," are probably fixed in number but varying in size, with discrete substructure and stable enzymatic components, held together by still undetermined structures or bonds.

\section{ACKNOWLEDGMENTS}

We wish to thank Dr. A. J. Richard for assistance with analytical ultracentrifugation, Dr. P. F. Mullinax for helpful criticism of this manuscript, Miss Lucille Gouldin for expert secretarial assistance, and Dr. G. Watson James, III, for continued interest and support.

This work was supported by U. S. Public Health Service grants CA-08482 and HE-09621 and the Blood Research Fund of the Medical College of Virginia.

\section{REFERENCES}

1. Valentine, W. N., W. S. Beck, J. H. Follette, H. Mills, and J. S. Lawrence. 1952. Biochemical studies in chronic myelocytic leukemia, polycythemia vera, and other idiopathic myeloproliferative disorders. Blood. 7: 959.

2. Seitz, I. F. 1965. Biochemistry of normal and leukemic leucocytes, thrombocytes, and bone marrow cells. In
Advances in Cancer Research. A. Haddow and S. Weinhouse, editors. Academic Press Inc., New York. 9: 303.

3. Scott, R. B. 1968. Glycogen in human peripheral blood leukocytes. I. Characteristics of the synthesis and turnover of glycogen in vitro. J. Clin. Invest. 47: 344.

4. Sidbury, J. B., Jr., M. Cornblath, J. Fisher, and E. House. 1961. Glycogen in erythrocytes of patients with glycogen storage disease. Pediatrics. 27: 103.

5. Cohn, Z. A., and J. G. Hirsch. 1960. The isolation and properties of the specific cytoplasmic granules of rabbit polymorphonuclear leukocytes. J. Exptl. Med. 112: 983.

6. Millinog, F. 1962. Further observations on a phosphate buffer for osmium solutions in fixation. In Fifth International Congress for Electron Microscopy, S. S. Breese, Jr., editor. Academic Press Inc., New York. 2: 8.

7. Erlandson, R. A. 1964. A new Maraglas, D. E. R 732, embedment for electron microscopy. J. Cell Biol 22: 704 .

8. Drochmans, P. 1962. Morphologie du glycogene. Etude au microscope électronique de colorations négatives du glucogene particulaire. J. Ultrastruct. Res. 6: 141.

9. Barber, A. A., W. W. Harris, and N. G. Anderson. 1966. Isolation of native glycogen by combined ratezonal and isopycnic centrifugation. In The Development of Zonal Centrifuges. N. G. Anderson, editor. National Cancer Institute Monograph. 21: 285.

10. Stetten, M. R., and DeW. Stetten, Jr. 1954. A study of the nature of glycogen regeneration in the intact animal. J. Biol. Chem. 207: 331.

11. Leloir, L. F., and S. H. Goldemberg. 1960. Synthesis of glycogen from uridine diphosphate glucose in liver. J. Biol. Chem. 235: 919.

12. Sutherland, E. W., and W. D. Wosilait. 1956. The relationship of epinephrine and glucagon to liver phosphorylase. I. Liver phosphorylase; preparation and properites. J. Biol. Chem. 218: 459. 